\title{
Change in Free Radical and Antioxidant Enzyme Levels in the Patients Undergoing Open Heart Surgery with Cardiopulmonary Bypass
}

\author{
Fevzi Sarper Türker, ${ }^{1}$ Ayşe Doğan, ${ }^{2}$ Gonca Ozan, ${ }^{3}$ Kurtuluş Kıbar, ${ }^{4}$ and Mine Erışır ${ }^{3}$ \\ ${ }^{1}$ Cardiovascular Surgery, Elazı̆̆ Medikal Park Hospital, 23000 Elazı̆̆, Turkey \\ ${ }^{2}$ Health High School and Physiotherapy and Rehabilitation Department, Bitlis Eren University, 13000 Bitlis, Turkey \\ ${ }^{3}$ Department of Biochemistry, Firat University Faculty of Veterinary Science, 23000 Elaziğ, Turkey \\ ${ }^{4}$ Biochemistry, Elazı̆̆ Medikal Park Hospital, 23000 Elazı̆̆, Turkey \\ Correspondence should be addressed to Fevzi Sarper Türker; sarperturker@gmail.com
}

Received 29 June 2016; Revised 7 November 2016; Accepted 29 November 2016

Academic Editor: Neelam Khaper

Copyright (C) 2016 Fevzi Sarper Türker et al. This is an open access article distributed under the Creative Commons Attribution License, which permits unrestricted use, distribution, and reproduction in any medium, provided the original work is properly cited.

\begin{abstract}
Objective. The purpose of this study is to determine the changes in oxidative damage and antioxidant parameters in open heart surgeries with cardiopulmonary bypass (CPB) in preoperative and early postoperative periods. Methods. A total of three consecutive arterial blood samples were obtained from the patients in the study group, in preoperative, early postoperative, and postoperative periods, respectively. Oxidative damage indicator (MDA) and antioxidant indicators (GPx, GSH, CAT, and SOD) were examined. Results. A statistically significant increase was observed in MDA level in postoperative period compared to preoperative and early postoperative periods. GSH levels and CAT activities increased significantly in early postoperative and postoperative periods. Analyses revealed an increase in GPx and SOD enzyme activities only in the postoperative period. Conclusion. Even though the increase in MDA level was suppressed by the increased GSH level and CAT activity like in early postoperative period, efficiency can be brought for the increases in insufficient significant antioxidant parameters in postoperative period by administering antioxidant supplements to the patients and thus the increase in MDA in postoperative period can be significantly suppressed.
\end{abstract}

\section{Introduction}

Free radicals are relatively reactive molecules. They are generally derived from oxygen so these molecules are called reactive oxygen species (ROS) [1]. ROS can be formed as products of normal metabolism such as aerobic metabolism in mitochondria in ATP production. However, ROS produced and released under normal conditions are eliminated by the defence mechanisms of the cells against ROS. These mechanisms include enzymatic and free radical scavenging activities. In a normal metabolism, the balance between ROS production and the defence mechanisms against ROS protects cells from damage. However, ROS levels may significantly increase and overwhelm the capacity of the defence system and, as a result, numerous cellular molecules such as lipids, proteins, and DNA may be affected [1].
Superoxide anion $\left(\mathrm{O}_{2}^{-\bullet}\right)$, hydrogen peroxide $\left(\mathrm{H}_{2} \mathrm{O}_{2}\right)$, hydroxyl radical $\left({ }^{\circ} \mathrm{OH}\right)$, and peroxynitrite $\left(\mathrm{ONOO}^{-}\right)$are the essential ROS types that cause oxidative damage in the heart [2]. Open heart surgeries performed with cardiopulmonary bypass induce oxidative stress. This situation is closely associated with excess ROS production [3]. Oxidative reaction causes damage in the cell function and may increase the complications during or after coronary artery bypass grafting (CABG) surgery $[4,5]$. Application of aortic cross clamp induces ischemia-reperfusion damage by causing an increase in stress during the surgery [6]. Oxidative stress indicators increasing in postoperative period such as xanthine oxidase, nuclear factor kappa B, and nicotinamide adenine dinucleotide phosphate oxidase are effective on pathogenesis of postoperative atrial fibrillation (POAF) [7]. Also the increase in ROS and superoxide anion production is caused by the 
atrial nicotinamide adenine dinucleotide phosphate oxidase and this is highly related to the development risk of POAF [8].

The presence of atherosclerotic coronary artery diseases is associated with inflammation and oxidative stress before the surgical intervention. Also, cardiac surgical intervention makes the patients more susceptible to diabetes, renal and lung diseases related to oxidative stress, and also excess formation of redox [2].

Antioxidant molecules may directly react with reactive radicals and may degrade. Thus, they can be converted to less active, long-lasting, and less dangerous new free radicals [2].

Propofol (2,6-diisopropylphenol) is generally used in heart surgery anaesthesia. Numerous in vitro and in vivo studies have proven the antioxidant effect of propofol [9]. It is reported that propofol protects the cells against oxidative stress by inhibiting the lipid peroxidation and increases the antioxidant capacity in human plasma [9]. Ischemia and reperfusion models in animal studies have revealed that propofol increases the antioxidant capacity of liver, kidney, heart, and lung tissues [9].

It is determined that the administration of L-arginine in the form of cardioplegia decreases the biochemical markers of oxidative stress and myocardial damage and this occurs with the increase in the SOD activity [10].

It is reported that primarily the excess ROS production is detected in coronary artery bypass operations [11]. Also limited data are obtained about the NO synthesis route and various components of oxidant/antioxidant balance in the circulation when the valve patients are compared with coronary patients and surgery patients are compared with healthy individuals [12]. Therefore the purpose of the present study was to determine the changes in oxidative damage and antioxidant parameters in early postoperative period and in the open heart surgeries performed with $\mathrm{CPB}$.

\section{Materials and Methods}

2.1. Population of the Study. In total, 26 patients undergoing open heart surgery with pump (14 males, 12 females) were included in the study. The study group consisted of all the emergent and elective cardiopulmonary bypass patients. CABG operation was applied to twenty patients among twenty-six patients. Among these 20 patients, 1 patient underwent AVR (aortic valve replacement) together with CABG and 1 patient underwent mitral ring annuloplasty together with CABG. 5 patients of the remaining 6 patients among twenty-six patients underwent MVR (mitral valve replacement). On the other hand, the remaining patient underwent AVR and MVR. Informed written consents of the patients were obtained. The ethics committee approval was obtained for the study (2015-15).

In the present study, we drew blood from each patient 3 times before the surgical intervention (preoperative period), at the end of the surgical intervention (early postoperative period), and approximately 24 hours after the surgical intervention (postoperative period). In these blood samples, the biochemical parameters malondialdehyde (MDA), an oxidative damage indicator, glutathione peroxidase (GPx), reduced glutathione (GSH), catalase (CAT), and superoxide dismutase (SOD), which are the antioxidant indicators, were examined.

2.2. Surgical Technique. The same surgical and anaesthetic team managed all patients. Anaesthesia was induced with fentanyl, propofol, and esmeron, whereas propofol infusion and fentanyl were used as maintenance. Before the anaesthesia, radial artery cannula was inserted under local anaesthesia for blood pressure monitoring. After the anaesthesia, central venous cannula and urine catheters were inserted and a median sternotomy was performed, followed by routine aortic and right atrial cannulation. Cardiopulmonary bypass (CPB) was carried out by using membrane oxygenators and moderate systemic hypothermia. Myocardial protection was achieved by antegrade mild hypothermic blood cardioplegia $\left(32^{\circ} \mathrm{C}\right)$ and was repeated every 20 minutes. Heparin $3.0 \mathrm{mg} / \mathrm{kg}$ was administered and the activated clotting time was maintained for $>400 \mathrm{sec}$ during the procedure. Heparin was neutralised with protamine at the ratio of $1: 1.3$ for 10 minutes after $\mathrm{CPB}$. After the surgery, all patients were followed up in the intensive care unit.

2.3. Sample Collection. Blood samples were brought to the laboratory right after they were taken in two heparincontaining experimental tubes through the cannula inserted in radial artery. One of the heparinised blood samples was used as the whole blood; the other heparinised blood sample was centrifuged at $3000 \mathrm{rpm}$ for 5 minutes, and its plasma was separated and then washed with physiological saline solution three times. Then, it was kept at the deep-freezer at $-80^{\circ} \mathrm{C}$ until biochemical analyses were performed.

\subsection{Biochemical Analyses}

2.4.1. Lipid Peroxidation. The MDA in plasma was determined according to the method of Placer et al. [13] with slight modifications. MDA created a pink complex with thiobarbituric acid (TBA) and the absorbance was read at $532 \mathrm{~nm}$. The plasma MDA content was expressed as $\mathrm{nmol} / \mathrm{mL}$.

2.4.2. GPx Activity. The Beutler method [14] was used for the GPx activity determination. GPx activity was spectrophotometrically calculated by the decrease in the optic density of the system at $340 \mathrm{~nm}$ following the NADPH oxidation. The GPx activity was calculated as $\mathrm{U} / \mathrm{g} \mathrm{Hb}$.

2.4.3. GSH Level. The GSH contents were screened based on the method of Sarita et al. [15] and were expressed as $\mu \mathrm{mol} / \mathrm{g}$ $\mathrm{Hb}$.

2.4.4. CAT Activity. The Aebi [16] method was used to measure CAT activity. The degradation rate of $\mathrm{H}_{2} \mathrm{O}_{2}$ by CAT was spectrophotometrically measured by means of the fact that $\mathrm{H}_{2} \mathrm{O}_{2}$ absorbed light at $240 \mathrm{~nm}$ wavelength. CAT activity was calculated as katal/g $\mathrm{Hb}$. 
TABLE 1: Demographic data of patients.

(a)

\begin{tabular}{|c|c|c|c|c|c|c|c|c|}
\hline \multirow[b]{2}{*}{$\begin{array}{l}\sum n \\
26\end{array}$} & \multirow[b]{2}{*}{ Groups } & \multirow[b]{2}{*}{$n / \%$} & \multicolumn{6}{|c|}{ Biochemical values $(X \pm S x)$} \\
\hline & & & $\begin{array}{c}\text { Urea } \\
(\mathrm{mg} / \mathrm{dL}) \\
(42.19 \pm 3.84) \\
P\end{array}$ & $\begin{array}{c}\text { Creatine } \\
(\mathrm{mg} / \mathrm{dL}) \\
(0.91 \pm 0.04) \\
P\end{array}$ & $\begin{array}{c}\text { AST } \\
(\mathrm{U} / \mathrm{L}) \\
(26.65 \pm 3.57) \\
P\end{array}$ & $\begin{array}{c}\text { ALT } \\
(\mathrm{U} / \mathrm{L}) \\
(28.46 \pm 3.71) \\
P\end{array}$ & $\begin{array}{c}\text { CRP } \\
(\mathrm{mg} / \mathrm{L}) \\
(1.15 \pm 0.38) \\
P\end{array}$ & $\begin{array}{c}\mathrm{EF} \\
(\%) \\
(0.50 \pm 0.02) \\
P\end{array}$ \\
\hline \multirow{2}{*}{ Gender } & Female & $12 / 46.2$ & 0.328 & 0.989 & 0.361 & 0.694 & 0.519 & 0.665 \\
\hline & Male & $14 / 53.8$ & $P>0.05$ & $P>0.05$ & $P>0.05$ & $P>0.05$ & $P>0.05$ & $P>0.05$ \\
\hline \multirow{2}{*}{ LIMA } & Yes & $10 / 38.5$ & 0.748 & 0.467 & 0.821 & 0.734 & 0.381 & 0.189 \\
\hline & No & $16 / 61.5$ & $P>0.05$ & $P>0.05$ & $P>0.05$ & $P>0.05$ & $P>0.05$ & $P>0.05$ \\
\hline \multirow{2}{*}{$\mathrm{DM}(\mathrm{mg} / \mathrm{dL})$} & Yes & $10 / 38.5$ & 0.659 & 0.965 & 0.157 & 0.263 & 0.346 & 0.083 \\
\hline & No & $16 / 61.5$ & $P>0.05$ & $P>0.05$ & $P>0.05$ & $P>0.05$ & $P>0.05$ & $P>0.05$ \\
\hline \multirow{2}{*}{ HT (mmHg) } & Yes & $19 / 73.1$ & 0.245 & 0.910 & 0.612 & 0.737 & 0.286 & 0.133 \\
\hline & No & $7 / 26.9$ & $P>0.05$ & $P>0.05$ & $P>0.05$ & $P>0.05$ & $P>0.05$ & $P>0.05$ \\
\hline \multirow{2}{*}{ Smoking } & Yes & $1 / 3.8$ & 0.606 & 0.970 & 0.524 & 0.815 & 0.629 & 0.667 \\
\hline & No & $25 / 96.2$ & $P>0.05$ & $P>0.05$ & $P>0.05$ & $P>0.05$ & $P>0.05$ & $P>0.05$ \\
\hline \multirow{2}{*}{ COPD } & Yes & $6 / 23.1$ & 0.592 & 0.318 & 0.281 & 0.279 & 0.634 & 0.882 \\
\hline & No & $20 / 76.9$ & $P>0.05$ & $P>0.05$ & $P>0.05$ & $P>0.05$ & $P>0.05$ & $P>0.05$ \\
\hline
\end{tabular}

(b)

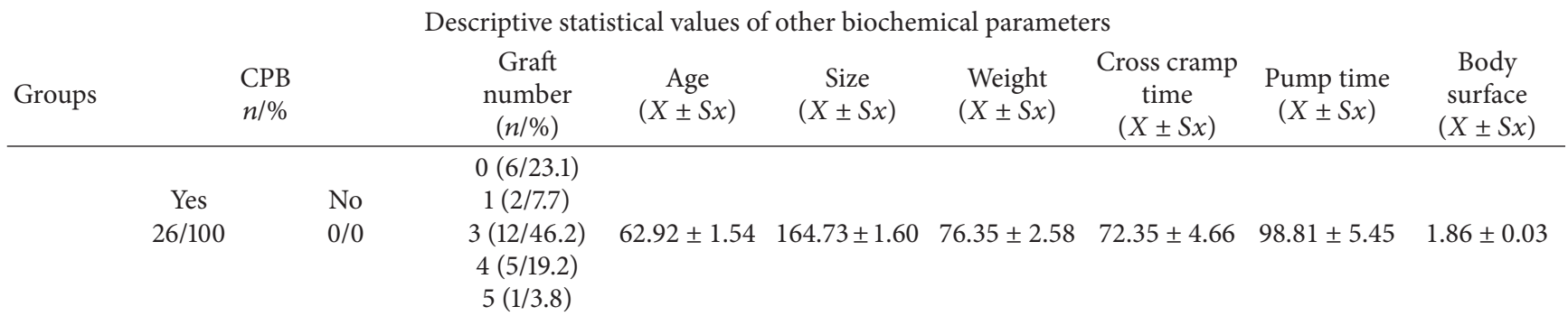

AST: aspartate amino transferase; ALT: alanine amino transferase; CRP: C-reactive protein; EF: ejection fraction; DM: diabetes mellitus; HT: hypertension; COPD: chronic obstructive pulmonary disease; CPB: cardiopulmonary bypass; LIMA: left internal mammary artery.

2.4.5. SOD Activity. The SOD enzyme activity was measured based on the nitroblue tetrazolium (NBT) degradation by the superoxide radical, which was produced with the xanthinexanthine oxidase system. The Formazan obtained at the end of the reactions exhibited a blue colour and was maximally absorbed at $560 \mathrm{~nm}$ [17]. The SOD enzyme activity was calculated as $\mathrm{U} / \mathrm{g} \mathrm{Hb}$.

2.5. Statistical Analysis. The SPSS package programme ( 15.0 for Windows) was used to carry out statistical analysis. Intergroup variance analyses were calculated by using the Paired $t$-test (Table 2). All results were shown as mean \pm standard deviation (SD) in Table 2. Independent samples $t$ test was performed to interpret the data in Table 1. All results were shown as mean \pm standard error (SEM) in Table 1. $P$ value less than 0.05 was considered statistically significant.

\section{Results and Discussion}

No statistical significance was found in the demographical findings of the patients included in the study $(P>0.05)$
(Table 1). Lack of any statistical change also in demographical findings showed that parameters in Table 1 did not have any effect on the formation of oxidative stress we aimed to determine in patients undergoing open heart surgery with cardiopulmonary bypass in the present study.

A statistically significant increase was determined in MDA level in postoperative period compared to preoperative and early postoperative periods, in GSH level and CAT activity in early postoperative and postoperative periods compared to preoperative period, and in GPx and SOD enzyme activities in postoperative period only compared to the preoperative period (Table 2 ).

Oxidative stress is an expression of oxidant/antioxidant imbalance [18]. Thus, the most correct approach for the determination of oxidative stress is to evaluate the oxidative damage parameter and the antioxidant parameters together. In the present study, we determined a significant increase in MDA level in postoperative period compared to preoperative and early postoperative periods. CABG induces the excessive production of ROS such as hydroxyl, hydrogen peroxide, hypochlorite, and superoxide from various enzymatic and cellular sources [3]. In the study of Mentese et al. [19] 
TABLE 2: Statistical comparison of oxidative and antioxidative parameters in preoperative, early postoperative, and postoperative periods.

\begin{tabular}{|c|c|c|c|c|}
\hline Parameters & $\begin{array}{l}\text { Preoperative } \\
\text { period }\end{array}$ & $\begin{array}{c}\text { Early } \\
\text { postoperative } \\
\text { period }\end{array}$ & $\begin{array}{l}\text { Postoperative } \\
\text { period }\end{array}$ & $P$ \\
\hline $\mathrm{MDA} \mathrm{nmol} / \mathrm{ml}$ & $4.14 \pm 0.65^{\mathrm{a}}$ & $4.31 \pm 0.64^{\mathrm{a}}$ & $4.66 \pm 0.73^{\mathrm{b}}$ & $P<0.05$ \\
\hline GPx U/g Hb & $42.21 \pm 8.67^{\mathrm{a}}$ & $45.59 \pm 10.72^{\mathrm{ab}}$ & $49.78 \pm 11.59^{\mathrm{b}}$ & $P<0.05$ \\
\hline $\mathrm{GSH} \mu \mathrm{mol} / \mathrm{g} \mathrm{Hb}$ & $1.65 \pm 0.63^{\mathrm{a}}$ & $3.10 \pm 1.36^{\mathrm{b}}$ & $3.52 \pm 2.11^{\mathrm{b}}$ & $P<0.001$ \\
\hline CAT k/g Hb & $30.39 \pm 15.54^{\mathrm{a}}$ & $43.19 \pm 18.98^{b}$ & $52.32 \pm 27.45^{\mathrm{b}}$ & $P<0.01$ \\
\hline SOD U/g Hb & $40.18 \pm 4.72^{\mathrm{a}}$ & $40.90 \pm 5.31^{\mathrm{ab}}$ & $45.47 \pm 9.07^{\mathrm{b}}$ & $P<0.05$ \\
\hline
\end{tabular}

The letters a and b show statistically different groups.

MDA: malondialdehyde; GPx: glutathione peroxidase; GSH: reduced glutathione; CAT: catalase; SOD: superoxide dismutase.

the increase in ROS was observed in ONCABG patients. Despite a significant increase in GSH level and CAT, GPx, and SOD activities in postoperative period, significant inhibition of increase in MDA in postoperative period was not shown in the present study. However, the significant increase in GSH level and CAT activity in early postoperative period significantly suppressed the increase in MDA in early postoperative period and stabilised the preoperative level. The increase in MDA level in postoperative period in the present study was compatible with the previous studies. It is reported that the most important factor in the degradation of oxidative balance in ONCABG is reperfusion [19]. It is considered that various factors such as surgical damage, $\mathrm{CPB}$, and ischemia-reperfusion damage cause oxidative stress in ONCABG patients [20]. Haemolysis occurring in CPB, ischemia-reperfusion damage, and activation of neutrophils are important factors in the formation of oxidative stress [2]. Pumping period in heart surgery and aortic cross clamp period are important factors in ischemia-reperfusion damage [21]. Previous studies revealed that the increase in total peroxide, 8 -isoprostane, nitrite-nitrate levels, and oxidative stress caused by the cross clamp period in CABG patients were correlated [22]. Again, in the study of Mentese et al. [19], it was found that the oxidant/antioxidant balance was not affected in ONCABG patients having short cross clamp periods (29 minutes). CPB is correlated with the formation of ROS production and oxidative stress [2]. The present study revealed that the increase in MDA was the main source of oxidative stress in $\mathrm{CPB}$ patients.

Oxidative stress induced by ischemia-reperfusion causes the development of postoperative atrial fibrillation (POAF) in postoperative period [6]. Being the most common arrhythmia observed after heart surgery, POAF is an important medical problem. Although there are some clinical and experimental studies regarding the pathogenesis of POAF, there is no sufficient number of studies that may explain the reason of POAF thoroughly [6]. Due to the complex and multifactorial nature of POAF, it is impossible to identify the optimal medical treatment [23]. Recent studies have highlighted the potential role of oxidative stress in the pathogenesis of POAF [6]. It is reported that excessive oxidative molecule formation contributed to the pathogenesis of POAF [24]. Ramlawi et al. [25] reported that the increase in total peroxide level in postoperative period was effective in POAF development.
Also in the study of Kim et al. [8] it was reported that the tissue level of NADPH oxidase in the left atrium that was related to lipid peroxidation significantly increased in POAF patients. The recent studies have emphasized the importance of oxidative stress in cardiovascular diseases but there is very limited data regarding the role of oxidative stress in patients undergoing a heart surgery [12]. In the previous studies and in the present study, the relationship of CPB with the oxidative stress formation and free radical production was specified. It is thought that this oxidative stress is an important factor in the formation of arteriosclerosis, coronary artery diseases, POAF, and other various cardiovascular diseases [26].

Administration of antioxidants as a supplement before surgical interventions by intravenous route or applying cardioplegia during the surgery may decrease the oxidative stress and ROS production in CPB [2]. Alternatively, the use of modified methods such as mini-bypass may relieve both the proinflammatory response and oxidative stress [2]. In the present study, even though the patients were not given any antioxidant supplement, self-ignition of their own defence mechanism supported the increase in GSH level and CAT activity. In accordance with the relevant studies in the literature, this suppressed the MDA levels significantly in early postoperative period for a while and preserved its level in the preoperative period [2]. However, the GSH level and CAT, GPx, and SOD activities increasing in postoperative period were not efficient in inhibiting the increase in MDA; thus, we think that a treatment modality comprising an antioxidant supplement that would likely prevent the formation of oxidative stress in postoperative period would be the treatment of choice. Optimally designed antioxidant strategies delineate a detailed application way or procedure and thus a more effective solution can be developed [5].

\section{Conclusions}

As a result, our study suggests that significant increase in the MDA level despite the increase in GSH level and CAT, GPx, and SOD activities among the antioxidant parameters especially in postoperative period is responsible for the undesired damage in patients undergoing $\mathrm{CPB}$ such as POAF. Consequently, this damage will impair the postoperative quality of life of the patients and even will endanger their lives. Based on the results of the present study, we advocate 
supporting the intrinsic antioxidant mechanism in postoperative period (GSH level; CAT, GPx, and SOD activities) via appropriate supplements so as to suppress the increase in MDA levels in postoperative period. This might both reduce occurrence of various lung and heart diseases after a heart surgery [2] and provide better quality of life and prolonged life. The present study is also important in terms of forming a basis for different studies on administration of antioxidant treatments in $\mathrm{CPB}$ patients especially in postoperative period.

\section{Competing Interests}

The authors declare that they have no competing interests.

\section{References}

[1] R. K. Gupta, A. K. Patel, N. Shah et al., "Oxidative stress and antioxidants in disease and cancer: a review," Asian Pacific Journal of Cancer Prevention, vol. 15, no. 11, pp. 4405-4409, 2014.

[2] M. Zakkar, G. Guida, M.-S. Suleiman, and G. D. Angelini, "Cardiopulmonary bypass and oxidative stress," Oxidative Medicine and Cellular Longevity, vol. 2015, Article ID 189863, 8 pages, 2015.

[3] G. Orhan, M. Sargin, S. Senay et al., "Systemic and myocardial inflammation in traditional and off-pump cardiac surgery," Texas Heart Institute Journal, vol. 34, no. 2, pp. 160-165, 2007.

[4] V. Cavalca, E. Sisillo, F. Veglia et al., "Isoprostanes and oxidative stress in off-pump and on-pump coronary bypass surgery," Annals of Thoracic Surgery, vol. 81, no. 2, pp. 562-567, 2006.

[5] J. Milei, P. Forcada, C. G. Fraga et al., "Relationship between oxidative stress, lipid peroxidation, and ultrastructural damage in patients with coronary artery disease undergoing cardioplegic arrest/reperfusion," Cardiovascular Research, vol. 73, no. 4, pp. 710-719, 2007.

[6] V. Oktay, O. Baydar, Ü. Y. Sinan et al., "The effect of oxidative stress related with ischemia-reperfusion damage on the pathogenesis of atrial fibrillation developing after coronary artery bypass graft surgery," Archives of The Turkish Society of Cardiology, vol. 42, no. 5, pp. 419-425, 2014.

[7] H. Oral, "Post-operative atrial fibrillation and oxidative stress: a novel causal mechanism or another biochemical epiphenomenon?" Journal of the American College of Cardiology, vol. 51, no. 1, pp. 75-76, 2008.

[8] Y. M. Kim, H. Kattach, C. Ratnatunga, R. Pillai, K. M. Channon, and B. Casadei, "Association of atrial nicotinamide adenine dinucleotide phosphate oxidase activity with the development of atrial fibrillation after cardiac surgery," Journal of the American College of Cardiology, vol. 51, no. 1, pp. 68-74, 2008.

[9] Y.-C. Li, P. Ridefelt, L. Wiklund, and G. Bjerneroth, "Propofol induces a lowering of free cytosolic calcium in myocardial cells," Acta Anaesthesiologica Scandinavica, vol. 41, no. 5, pp. 633-638, 1997.

[10] D. T. Andrews, J. Sutherland, P. Dawson, A. G. Royse, and C. F. Royse, "L-arginine cardioplegia reduces oxidative stress and preserves diastolic function in patients with low ejection fraction undergoing coronary artery surgery," Anaesthesia and Intensive Care, vol. 40, no. 1, pp. 99-106, 2012.

[11] M. E. Callister, A. Burke-Gaffney, G. J. Quinlan et al., "Extracellular thioredoxin levels are increased in patients with acute lung injury," Thorax, vol. 61, no. 6, pp. 521-527, 2006.
[12] W.-J. van Boven, W. B. Gerritsen, F. G. Waanders, F. J. Haas, and L. P. Aarts, "Mini extracorporeal circuit for coronary artery bypass grafting: initial clinical and biochemical results: a comparison with conventional and off-pump coronary artery bypass grafts concerning global oxidative stress and alveolar function," Perfusion, vol. 19, no. 4, pp. 239-246, 2004.

[13] Z. A. Placer, L. L. Cushman, and B. C. Johnson, "Estimation of product of lipid peroxidation (malonyl dialdehyde) in biochemical systems," Analytical Biochemistry, vol. 16, no. 2, pp. 359-364, 1966.

[14] A. Beutler, A Manual of Biochemical Methods, Grunef Strottan, New York, NY, USA, 2nd edition, 1975.

[15] C. Sarita, L. Sava, V. Saxena, S. Pillai, A. Sontakke, and D. Ingole, "Reduced Glutathione: importance of specimen collection," International Journal of Clinical Biochemistry, vol. 20, no. 1, pp. 150-152, 2005.

[16] H. Aebi, "Catalase in vitro," Methods in Enzymology, vol. 105, pp. 121-126, 1984.

[17] Y. Sun, L. W. Oberley, and Y. Li, "A simple method for clinical assay of superoxide dismutase," Clinical Chemistry, vol. 34, no. 3, pp. 497-500, 1988.

[18] M. Rabus, R. Demirbağ, Y. Sezen et al., "Plasma and tissue oxidative stress index in patients with rheumatic and degenerative heart valve disease," Turk Kardiyoloji Dernegi Arsivi, vol. 36, no. 8, pp. 536-540, 2008.

[19] U. Mentese, O. V. Dogan, I. Turan et al., "Oxidant-antioxidant balance during on-pump coronary artery bypass grafting," The Scientific World Journal, vol. 2014, Article ID 263058, 5 pages, 2014.

[20] K. Berg, R. Haaverstad, R. Astudillo et al., "Oxidative stress during coronary artery bypass operations: importance of surgical trauma and drug treatment," Scandinavian Cardiovascular Journal, vol. 40, no. 5, pp. 291-297, 2006.

[21] D. R. Van Wagoner, "Oxidative stress and inflammation in atrial fibrillation: role in pathogenesis and potential as a therapeutic target," Journal of Cardiovascular Pharmacology, vol. 52, no. 4, pp. 306-313, 2008.

[22] A. S. Kunt, S. Selek, H. Celik, D. Demir, O. Erel, and M. H. Andac, "Decrease of total antioxidant capacity during coronary artery bypass surgery," Mount Sinai Journal of Medicine, vol. 73, no. 5, pp. 777-783, 2006.

[23] M. Jakubová, P. Mitro, B. Stančák et al., "The occurrence of postoperative atrial fibrillation according to different surgical settings in cardiac surgery patients," Interactive Cardiovascular and Thoracic Surgery, vol. 15, no. 6, pp. 1007-1012, 2012.

[24] J.-Y. Youn, J. Zhang, Y. Zhang et al., "Oxidative stress in atrial fibrillation: an emerging role of NADPH oxidase," Journal of Molecular and Cellular Cardiology, vol. 62, pp. 72-79, 2013.

[25] B. Ramlawi, H. Otu, S. Mieno et al., "Oxidative stress and atrial fibrillation after cardiac surgery: a case-control study," Annals of Thoracic Surgery, vol. 84, no. 4, pp. 1166-1173, 2007.

[26] V. Cavalca, E. Tremoli, B. Porro et al., "Oxidative stress and nitric oxide pathway in adult patients who are candidates for cardiac surgery: patterns and differences," Interactive Cardiovascular and Thoracic Surgery, vol. 17, no. 6, pp. 923-930, 2013. 


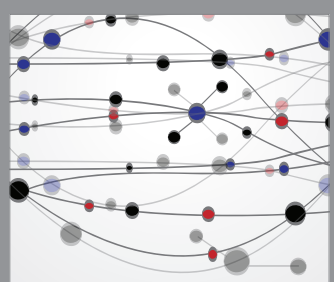

The Scientific World Journal
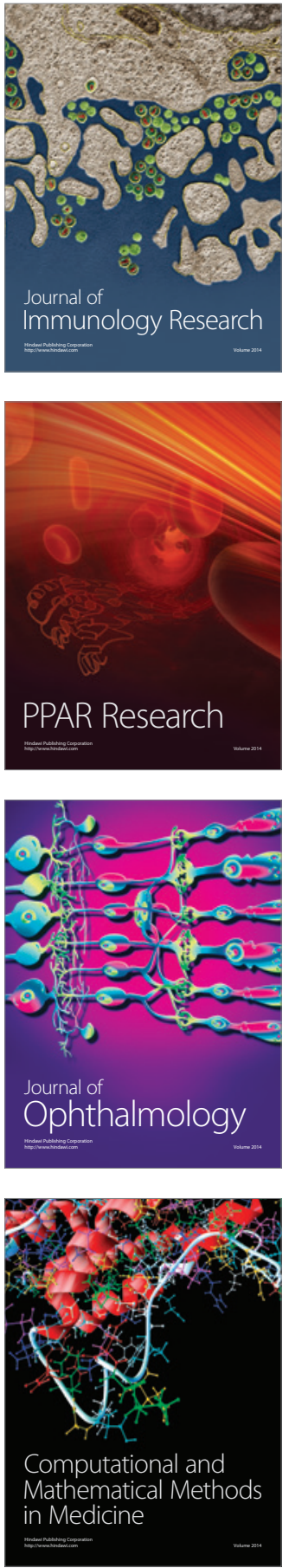

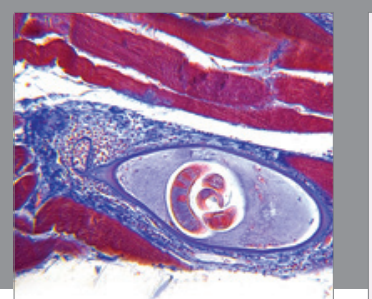

Gastroenterology Research and Practice

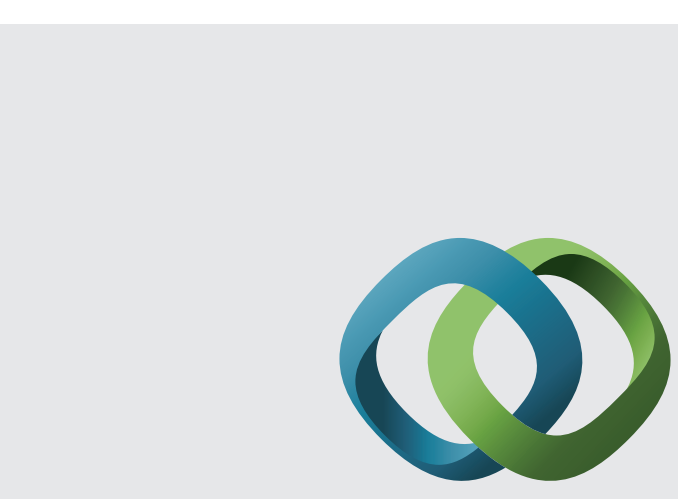

\section{Hindawi}

Submit your manuscripts at

http://www.hindawi.com
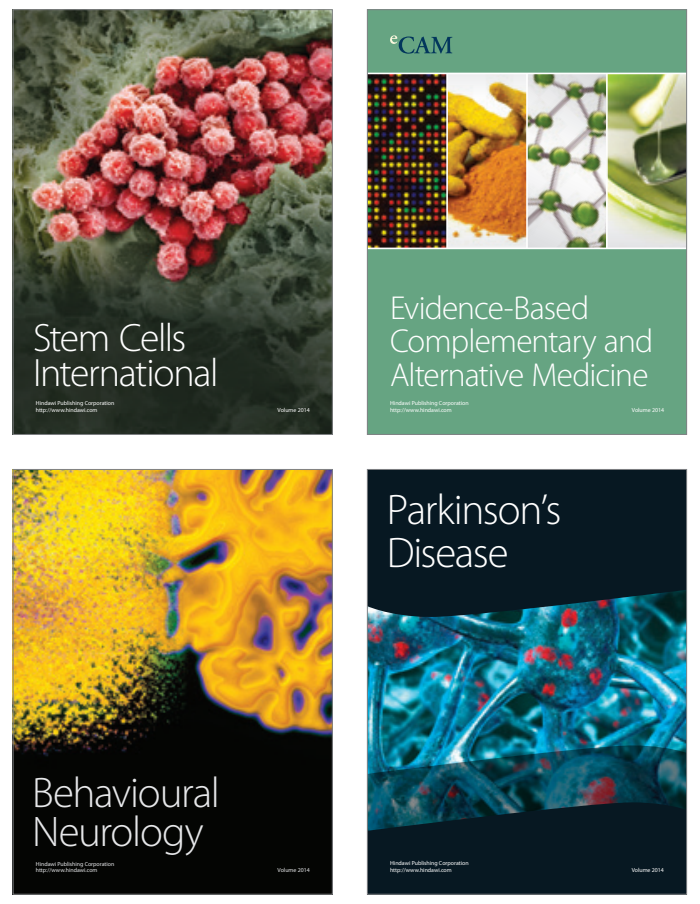
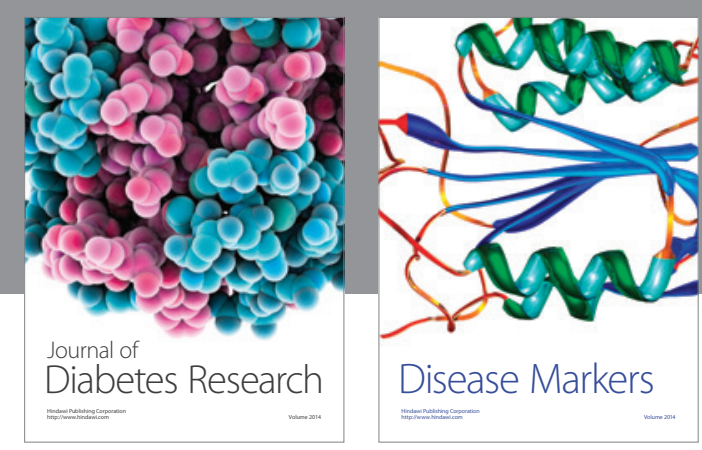

Disease Markers
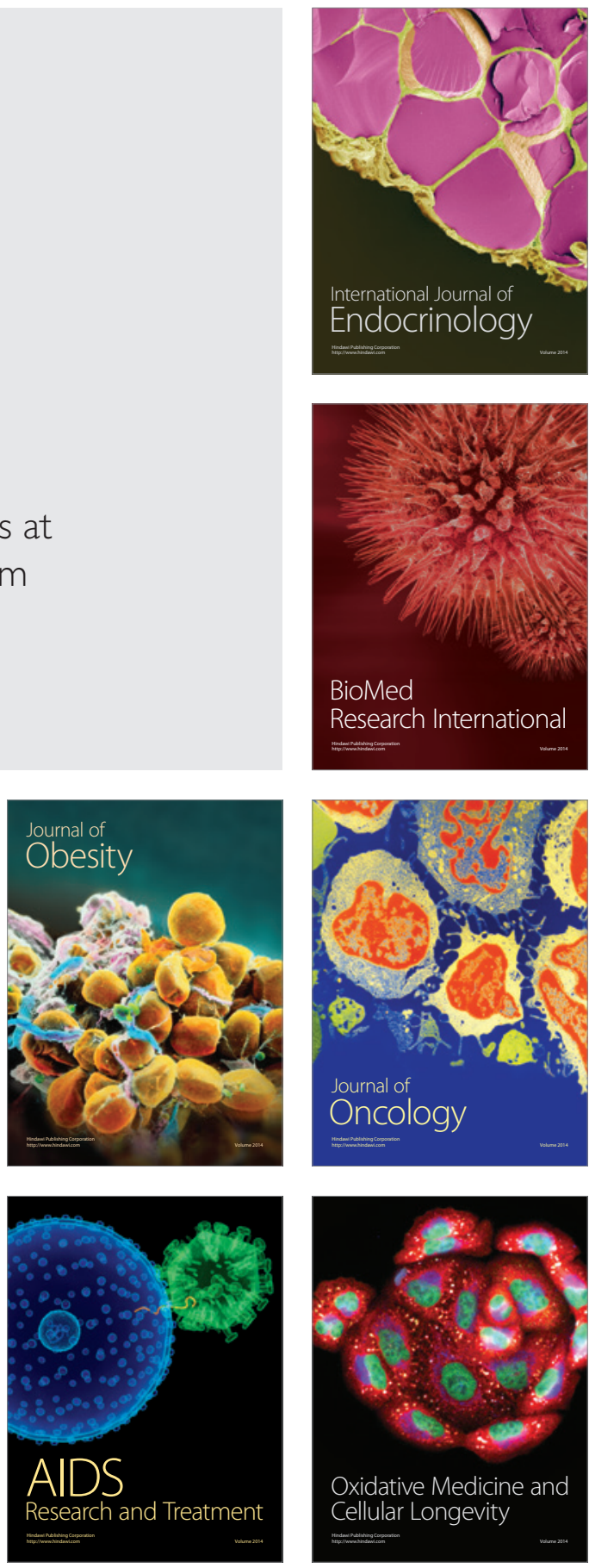